\title{
VALUE CHAIN TRANSFORMATION
}

\author{
Ricardo Hernandez, Ben Belton, Thomas Reardon, \\ Chaoran Hu, Xiaobo Zhang, and Akhter Ahmed
}

\section{Introduction}

The majority of literature on aquaculture in Bangladesh focuses on "microsocioeconomics" and "value chains" (VCs) and tends to have a static perspective. However, this approach is at odds with several important emerging trends (Ali 1997; Ali, Haque, and Belton 2013). First, aquaculture is growing fast in Asia. From 1984 to 2014, Bangladesh's farmed fish jumped from 124,000 metric tons to 1.96 million metric tons, increasing by 1,580 percent. As a result, aquaculture now accounts for 55 percent of Bangladesh's fish supply, up from just 16 percent three decades ago (Bangladesh, DoF 1994, 1997, 2006, 2015). Second, there has been a rapid shift from home consumption (from one's own pond) to purchasing farmed fish from the market - consumers of farmed fish got 92 percent of it via purchase from the market in 2010 versus 79 percent in 2000 (data extracted from BBS 2012). This implies that "commercial aquaculture" (which we define simply as fish farming output that is sold, with no specification of the farm size) has moved to be far more important than subsistence fish farming.

Third, there has been rapid diversification of farmed fish composition. This involved a shift from traditional carps to introduced species (tilapia and pangas) that lend themselves better than carp to intensification through higher stocking densities combined with the use of manufactured feeds. This is an example of what economics terms the "product cycle," which has not been studied in Asia as an evolution in the market. Fourth, far less studied is a rapid transformation of the structure of domestic aquaculture VCs in Asia, shown by our survey results for Bangladesh. As the sector expanded, rapid commercialization and diversification of species occurred, and there was a proliferation of upstream and downstream VC actors and in some cases concentration among them.

The great majority of these changes have been driven by small and medium-size enterprises. These changes can be categorized as "immanent 
development" (Belton and Little 2011) — that is, development unplanned and undirected by government or NGOs-arising mainly from private household, firm, and community choices, driven by changes in demand, technology, communications, and infrastructure, and abetted by propitious policies. This can be contrasted with "interventionist development" (NGO projects, centralized planning by governments). The "quiet revolution" in agrifood systems in Asia-observed by Reardon et al. (2012) in rice and potatoes in Bangladesh, China, and India-is symptomatic of these broad processes of immanent development led by small farms and small off-farm enterprises. We argue that aquaculture in Bangladesh has experienced a similar quiet revolution.

This chapter addresses these four trends as a confluence, with an emphasis on the latter one (structure and conduct change in the aquaculture VC in Bangladesh), with a focus on fish. We address two questions and thus important gaps in knowledge about VC transformation. First, how is the domestic fish value chain restructuring? Second, how is the conduct of the segments changing in terms of product composition and technology? It is beyond the scope of this chapter to explore impacts on farmers or consumers of these VC changes-that is an agenda for further research. The chapter proceeds as follows. First, we outline the characteristics of the main geographical zones or clusters included in the study, where high concentrations of farms and other off-farm VC actors occur. Second, we address the structure and conduct changes in the various segments of the aquaculture VCs in these zones serving rural and urban markets. Third, we conclude with policy implications.

\section{The Study Areas and Their Characteristics}

Using the VC surveys discussed in Chapter 2, we define the VC actors by size, in order to categorize and observe VC transformations (Table 3.1). Next we examine the descriptive statistics of these aquaculture regions over time, stratified by zones, to determine basic trends in fish farming production (Table 3.2).

Table 3.2 shows selected characteristics of the four zones or clusters. Several points stand out. First, there is a fairly homogenous picture across zones in terms of general characteristics. This may be because all the areas identified as containing high densities of ponds are located in major lowland rice-growing areas with relatively easy access to the capital city, Dhaka. The study zones have broadly similar socioeconomic conditions, as compared with more peripheral and remote areas with less conducive geographies and ecology for aquaculture. 
TABLE 3.1 Definitions of actor size, by actor type

\begin{tabular}{|c|c|c|c|}
\hline Actor & Defining characteristic & Size category & Definition \\
\hline \multirow[t]{3}{*}{ Hatcheries } & \multirow[t]{3}{*}{ Total production area (ha) } & Small & $<0.04$ \\
\hline & & Medium & $0.04-0.8$ \\
\hline & & Large & $>0.8$ \\
\hline \multirow[t]{3}{*}{ Feed mills } & \multirow{3}{*}{$\begin{array}{l}\text { Total metric tons of feed } \\
\text { produced per month }\end{array}$} & Small & $<50$ \\
\hline & & Medium & 50 to 300 \\
\hline & & Large & $>300$ \\
\hline \multirow[t]{3}{*}{ Input dealers } & \multirow{3}{*}{$\begin{array}{l}\text { Total metric tons of feed } \\
\text { sold per month }\end{array}$} & Small & $<10$ \\
\hline & & Medium & 10 to 100 \\
\hline & & Large & $>100$ \\
\hline \multirow[t]{3}{*}{ Farmers } & \multirow[t]{3}{*}{ Total pond area (ha) } & Small & $<0.2$ \\
\hline & & Medium & $0.2-0.8$ \\
\hline & & Large & $>0.8$ \\
\hline \multirow[t]{3}{*}{ Traders } & \multirow{3}{*}{$\begin{array}{l}\text { Total metric tons of fish } \\
\text { traded per week }\end{array}$} & Small & $<1$ \\
\hline & & Medium & 1 to 5 \\
\hline & & Large & $>5$ \\
\hline
\end{tabular}

Source: Authors' calculations based on the farm household component of the Bangladesh fish value chain survey conducted by the International Food Policy Research Institute in 2013.

The study zones are of similar size. They have population densities of around 1,400 persons per square kilometer, except for the Southwest (with 800 persons per square kilometer). The lower population density in the Southwest is a function of a large part of the land in its three districts being comprised of uninhabited mangrove forest. Income differences over zones are proxied by differences in monthly per capita expenditure, which is similar across the zones at roughly US $\$ 2,700$ per year for a five-person household. Road density per square kilometer corresponds closely with differences in population density (lower in the Southwest, similar in other zones). The share of paved roads in total roads jumped dramatically over the 10 years from 2004 to 2014 in all zones, to more than 80 percent. The North, which had the highest share of paved roads in 2014, at 92 percent, also had the highest share in 2004, with 77 percent, indicating a historically well-developed transport infrastructure. 
TABLE 3.2 Zone characteristics

\begin{tabular}{|c|c|c|c|c|c|}
\hline Item & Southwest & $\begin{array}{l}\text { South } \\
\text { Center }\end{array}$ & North & East & All \\
\hline Total area $\left(\mathrm{km}^{2}\right)$ & 8,710 & 8,492 & 13,752 & 15,809 & 46,763 \\
\hline Population density (inhabitants/km²) & 757 & 1,354 & 1,388 & 1,445 & 1,302 \\
\hline Monthly per capita expenditure (BDT) & 2,359 & 2,842 & 2,621 & 2,932 & 2,730 \\
\hline \multicolumn{6}{|l|}{ Road density (km of roads/km²) } \\
\hline 2004 & 0.11 & 0.18 & 0.19 & 0.21 & 0.18 \\
\hline 2009 & 0.12 & 0.19 & 0.21 & 0.20 & 0.19 \\
\hline 2014 & 0.12 & 0.19 & 0.22 & 0.22 & 0.20 \\
\hline \multicolumn{6}{|l|}{ Share of paved roads in total roads (\%) } \\
\hline 2004 & 54 & 60 & 77 & 55 & 63 \\
\hline 2009 & 79 & 84 & 92 & 78 & 84 \\
\hline 2014 & 81 & 82 & 92 & 82 & 85 \\
\hline \multicolumn{6}{|l|}{ Aquaculture area (ha) } \\
\hline 2004 & 168,493 & 38,614 & 39,795 & 113,994 & 360,896 \\
\hline 2009 & 168,560 & 45,529 & 40,619 & 113,337 & 368,044 \\
\hline 2014 & 220,223 & 116,809 & 126,667 & 111,794 & 575,493 \\
\hline \multicolumn{6}{|l|}{ Fish pond area (ha) } \\
\hline 2004 & 11,815 & 33,570 & 39,758 & 68,037 & 153,180 \\
\hline 2009 & 16,630 & 46,368 & 60,071 & 48,901 & 171,970 \\
\hline 2014 & 24,247 & 44,257 & 60,110 & 71,493 & 200,107 \\
\hline Change in pond area (\%) & 105.2 & 31.8 & 51.2 & 5.1 & 30.6 \\
\hline \multicolumn{6}{|l|}{ Aquaculture production (MT) } \\
\hline 2004 & 125,677 & 89,953 & 103,824 & 219,135 & 538,589 \\
\hline 2009 & 140,289 & 114,416 & 121,491 & 231,098 & 607,294 \\
\hline 2014 & 225,798 & 269,568 & 469,830 & 300,914 & $1,266,110$ \\
\hline \multicolumn{6}{|l|}{ Fish production (MT) } \\
\hline 2004 & 37,264 & 87,852 & 101,110 & 177,415 & 403,641 \\
\hline 2009 & 32,313 & 149,843 & 292,211 & 156,821 & 631,188 \\
\hline 2014 & 56,107 & 182,123 & 398,979 & 240,468 & 877,677 \\
\hline Change in fish production (\%) & 50.6 & 107.3 & 294.6 & 35.5 & 117.4 \\
\hline
\end{tabular}

Source: BBS 2007, 2012, and 2016.

Note: Aquaculture area is the total area of the two main culture systems—-fish pond, shrimp/prawn farms—plus other minor production systems: pen and cage culture, culture-based fisheries in oxbow lakes (baor) and seasonal floodplains. BDT = Bangladeshi taka. 
Second, as noted earlier, fish farming has developed rapidly in Bangladesh since the 1990s, accelerating during the 2000s. This is reflected in the table in the expansion of fish pond area, which grew by 31 percent across the four zones (fastest in the Southwest and North, with increases of 105 percent and 51 percent, respectively, and lowest in the East, which grew only 5 percent). Fish pond output increased more rapidly than pond area, indicating that intensification was taking place. Output rose 117 percent overall, with the greatest increase in the North (295 percent) and South Center regions (107 percent) and lowest in the East (36 percent).

Third, fish production yields (per hectare of pond surface) in the zones varied considerably, with 2.3 metric tons per hectare in the Southwest, 3.4 in the East, 4 in the South Center, and 6.7 in the North. As a result of its high productivity, the North cluster (mainly Mymensingh) accounted for 45.5 percent of fish production in the four zones, from 30 percent of the pond area. Large differences in land (pond) yields across zones reflect differences in the technologies deployed, with the North being the most "advanced" zone, the "cradle" of intensive aquaculture in Bangladesh. This status is partly path dependent, reflecting a number of initial conditions, including (1) superior road access to the capital city Dhaka (ADB 2005); (2) a history of commercially oriented "Green Revolution" rice farming in such districts as Bogra (Crow 2001); and (3) the location of key institutions such as the Bangladesh Fisheries Research Institute in Mymensingh district, which played an important role in the transfer of seed and production technologies for new species to well-connected farmers and hatcheries in the area (Belton and Little 2011).

\section{Transformation of Structure and Conduct in the Value Chain}

This section is organized into three subsections. The first focuses on growth and concentration, the second focuses on commercialization and spatial elongation, and the third subsection focuses on technological cum product composition/product cycle change and patterns.

\section{Growth and Concentration}

There has been rapid development and proliferation of the off-farm components of the fish value chain in the study zones. The combination of that plus the rapid rise in aquaculture farms in those areas is creating dense clusters of $\mathrm{VC}$ actors in these places. This has occurred upstream in the value chain (in hatcheries, feed milling, feed wholesale and retail, and farms) as well as 
midstream and downstream (in transport, rural and urban wholesale markets [arat] and traders [aratdar], and retailing). In all segments astounding development of these enterprises-and acceleration of that development over the past 5 to 10 years-has taken place. Tables 3.3, 3.4, 3.5, 3.6, 3.7, 3.8, and 3.9 show structural change, proxied by a number of different actors and shares of the size strata in the total number. We discuss this segment by segment, from upstream to midstream.

\section{HATCHERY SEGMENT RESTRUCTURING}

Over the four zones, our survey data show that there was a 207 percent increase in hatcheries over the 10 years (Table 3.3), with the rate of growth fastest in the Southwest (314 percent) and slowest in the South Center (150 percent). This rate of expansion exceeded that of either fish farm numbers (up 63 percent) or farm output (up 117 percent), thus suggesting a shift to purchased seed. Big hatcheries ( $\geq 0.8$ hectares) accounted for 53 percent of hatchery area in 2014, a bit lower than 58 percent in 2004, showing slight deconcentration. The share of numbers of big hatcheries in all hatcheries over all zones together dropped a bit, from 15 percent in 2004 to 15 percent in 2014. But still, by 2014 the hatchery segment was concentrated: the big hatcheries had 19 percent of numbers but 53 percent of total hatchery area.

The rapid increase in hatchery numbers, outstripping farm growth, and the tendency toward size deconcentration may indicate the spread of new small and medium-size hatcheries beyond original "core" clusters. The preponderance of hatcheries in northern Bangladesh reflects the emergence of Bogra and Mymensingh as major producers of seed, for historical reasons, as Bogra hatcheries export pangas seed to India in addition to serving the domestic market (Ali, Haque, and Belton 2013).

Hatchery growth has been accompanied by rapid expansion of nurseries, particularly in nearby areas, which buy hatchlings or fry from hatcheries and raise them to fingerling size for sale to farms directly, via small traders (patil wallah), or over longer distances by larger agents. Overall (from the survey but not shown in the tables), 53 percent of the seed produced by hatcheries is sold to fingerling traders, and 44 percent direct to farmers and nurseries.

\section{FEED MILL SEGMENT RESTRUCTURING}

For feed mills (Table 3.4), as with hatcheries, there is a high degree of spatial concentration in the North, where 62 percent of the country's mills are located. Just under one-third of mills are located in the East, around Chittagong, another major industrial center, Bangladesh's second city and main seaport. 
TABLE 3.3 Structural change in hatchery clusters over 10 years

\begin{tabular}{|c|c|c|c|c|c|c|c|c|c|c|c|c|}
\hline \multirow[b]{4}{*}{ Zone } & \multicolumn{12}{|c|}{ Hatcheries } \\
\hline & & & & & & & are in & total nu & umber ( & & & \\
\hline & \multicolumn{3}{|c|}{ Total number } & \multicolumn{3}{|c|}{ of small } & \multicolumn{3}{|c|}{ of medium } & \multicolumn{3}{|c|}{ of large } \\
\hline & 2004 & 2009 & 2014 & 2004 & 2009 & 2014 & 2004 & 2009 & 2014 & 2004 & 2009 & 2014 \\
\hline Southwest & 7 & 14 & 22 & 0 & 0 & 0 & 88 & 86 & 91 & 13 & 14 & 9 \\
\hline South Center & 80 & 102 & 120 & 7 & 7 & 5 & 67 & 65 & 75 & 25 & 28 & 20 \\
\hline North & 177 & 281 & 410 & 49 & 50 & 54 & 33 & 32 & 31 & 18 & 18 & 14 \\
\hline East & 104 & 142 & 209 & 37 & 39 & 39 & 43 & 43 & 46 & 20 & 18 & 15 \\
\hline \multirow[t]{4}{*}{ All } & 368 & 539 & 761 & 44 & 46 & 51 & 37 & 35 & 35 & 19 & 18 & 15 \\
\hline & & & & \multicolumn{9}{|c|}{ Share in total production area (\%) } \\
\hline & & & & \multicolumn{3}{|c|}{ of small } & \multicolumn{3}{|c|}{ of medium } & \multicolumn{3}{|c|}{ of large } \\
\hline & & & & 2004 & 2009 & 2014 & 2004 & 2009 & 2014 & 2004 & 2009 & 2014 \\
\hline Southwest & & & & 0 & 0 & 0 & 71 & 68 & 79 & 29 & 32 & 21 \\
\hline South Center & & & & 0 & 0 & 0 & 48 & 45 & 57 & 52 & 55 & 43 \\
\hline North & & & & 3 & 3 & 3 & 38 & 38 & 42 & 60 & 59 & 55 \\
\hline East & & & & 2 & 2 & 2 & 42 & 45 & 50 & 57 & 53 & 48 \\
\hline All & & & & 2 & 2 & 3 & 40 & 40 & 44 & 58 & 58 & 53 \\
\hline
\end{tabular}

Source: Authors' calculations based on the mesolevel component of the Bangladesh fish value chain survey conducted by the International Food Policy Research Institute in 2014.

The number of feed mills jumped even faster than that of hatcheries, reflecting the later introduction and adoption of feeds as compared to hatchery seed. Interviews conducted during our rapid reconnaissance indicated that there were seven to eight feed mills (defined as formal firms, not backyard feed operations on farms) in Bangladesh in 2003. The number increased 15-fold to about 100 mills by 2004 . Table 3.4 indicates numbers of mills increasing by 268 percent over the period to 255 and rising fast in all zones.

The feed mill segment is even more concentrated than the hatchery segment for two reasons. First, many have developed from the addition of lines by existing large domestic poultry feed firms, with a head start in the industry, from major investments by foreign companies. Second, there are economies of scale involved in sourcing raw materials, maintaining high utilization rates, and spreading fixed costs over a large volume. Big mills accounted for 67 percent of total feed production volume in 2014, although the share of volume had barely changed from 2004 (66 percent). 
TABLE 3.4 Structural change in feed mill clusters over 10 years

\begin{tabular}{|c|c|c|c|c|c|c|c|c|c|c|c|c|}
\hline \multirow[b]{4}{*}{ Zone } & \multicolumn{12}{|c|}{ Feed mills } \\
\hline & \multirow{2}{*}{\multicolumn{3}{|c|}{ Total number }} & \multicolumn{9}{|c|}{ Share in total number (\%) } \\
\hline & & & & \multicolumn{3}{|c|}{$\begin{array}{c}\text { of small } \\
\text { (<50 MT) }\end{array}$} & \multicolumn{3}{|c|}{$\begin{array}{l}\text { of medium } \\
\text { (50-300 MT) }\end{array}$} & \multicolumn{3}{|c|}{$\begin{array}{c}\text { of large } \\
\text { (> } 300 \text { MT) }\end{array}$} \\
\hline & 2004 & 2009 & 2014 & 2004 & 2009 & 2014 & 2004 & 2009 & 2014 & 2004 & 2009 & 2014 \\
\hline Southwest & 4 & 5 & 7 & 68 & 56 & 49 & 23 & 37 & 46 & 9 & 7 & 5 \\
\hline South Center & 2 & 7 & 9 & 0 & 29 & 22 & 50 & 43 & 56 & 50 & 29 & 22 \\
\hline North & 62 & 100 & 154 & 30 & 30 & 27 & 40 & 37 & 38 & 30 & 34 & 35 \\
\hline East & 28 & 43 & 84 & 43 & 30 & 45 & 26 & 38 & 27 & 31 & 32 & 28 \\
\hline \multirow[t]{4}{*}{ All } & 95 & 155 & 255 & 35 & 30 & 33 & 35 & 37 & 35 & 30 & 32 & 32 \\
\hline & & & & \multicolumn{9}{|c|}{ Share of total volume (\%) } \\
\hline & & & & \multicolumn{3}{|c|}{ of small } & \multicolumn{3}{|c|}{ of medium } & \multicolumn{3}{|c|}{ of large } \\
\hline & & & & 2004 & 2009 & 2014 & 2004 & 2009 & 2014 & 2004 & 2009 & 2014 \\
\hline Southwest & & & & 17 & 13 & 11 & 41 & 59 & 71 & 42 & 28 & 18 \\
\hline South Center & & & & 0 & 3 & 3 & 28 & 36 & 48 & 72 & 61 & 49 \\
\hline North & & & & 4 & 3 & 3 & 33 & 29 & 29 & 64 & 68 & 69 \\
\hline East & & & & 6 & 3 & 6 & 23 & 30 & 26 & 71 & 66 & 68 \\
\hline All & & & & 4 & 3 & 4 & 30 & 30 & 29 & 66 & 66 & 67 \\
\hline
\end{tabular}

Source: Authors' calculations based on the mesolevel component of the Bangladesh fish value chain survey conducted by the International Food Policy Research Institute in 2014.

\section{FEED DEALER SEGMENT RESTRUCTURING}

Input dealers (Table 3.5) are mainly feed dealers who distribute feed for mills. They are numerous, totaling 15,483 over the four zones, up from 7,690 in 2004 (hence a 2 -fold growth versus a 1.6-fold growth of farmers). Like hatcheries and mills, input dealers are concentrated in the North (home to 56 percent of dealers but only 35 percent of farmers). But they are underrepresented relative to farmers in the Southwest and the South Center, perhaps unsurprisingly given that fish yields (and thus by implication feed use) are lowest in these two zones. Some concentration in market share is present, with larger dealers having 54 percent of the traded volume in 2004. Their share dropped to 48 percent in 2014 as many new small dealers entered the scene.

\section{FISH FARM SEGMENT STRUCTURE RESTRUCTURING}

Fish farmers are more evenly distributed spatially than other value chain actors over the four clusters (Table 3.6), with the North accounting for 36 percent and the Southwest and the South Center 29 percent each but the East only 9 percent. The total number of fish farmers across the four zones 
TABLE 3.5 Structural change in feed dealer clusters over 10 years

\begin{tabular}{|c|c|c|c|c|c|c|c|c|c|c|c|c|}
\hline \multirow[b]{4}{*}{ Zone } & \multicolumn{12}{|c|}{ Feed dealers } \\
\hline & \multirow{2}{*}{\multicolumn{3}{|c|}{ Total number }} & \multicolumn{9}{|c|}{ Share in total number (\%) } \\
\hline & & & & \multicolumn{3}{|c|}{$\begin{array}{c}\text { of small } \\
(<10 \mathrm{MT})\end{array}$} & \multicolumn{3}{|c|}{$\begin{array}{l}\text { of medium } \\
(10-100 \mathrm{MT})\end{array}$} & \multicolumn{3}{|c|}{$\begin{array}{c}\text { of large } \\
\text { (> 100 MT) }\end{array}$} \\
\hline & 2004 & 2009 & 2014 & 2004 & 2009 & 2014 & 2004 & 2009 & 2014 & 2004 & 2009 & 2014 \\
\hline Southwest & 1,373 & 1,915 & 2,461 & 66 & 69 & 65 & 31 & 29 & 31 & 3 & 3 & 4 \\
\hline South Center & 1,428 & 2,109 & 3,111 & 50 & 48 & 43 & 42 & 45 & 48 & 8 & 7 & 9 \\
\hline North & 4,308 & 6,835 & 8,448 & 43 & 41 & 44 & 32 & 36 & 36 & 25 & 23 & 20 \\
\hline East & 581 & 907 & 1,464 & 69 & 62 & 60 & 28 & 32 & 34 & 3 & 5 & 7 \\
\hline \multirow[t]{4}{*}{ All } & 7,690 & 11,766 & 15,483 & 50 & 49 & 49 & 34 & 36 & 37 & 16 & 15 & 14 \\
\hline & & & & \multicolumn{9}{|c|}{ Share in total volume (\%) } \\
\hline & & & & \multicolumn{3}{|c|}{ of small } & \multicolumn{3}{|c|}{ of medium } & \multicolumn{3}{|c|}{ of large } \\
\hline & & & & 2004 & 2009 & 2014 & 2004 & 2009 & 2014 & 2004 & 2009 & 2014 \\
\hline Southwest & & & & 13 & 15 & 12 & 68 & 67 & 64 & 19 & 19 & 23 \\
\hline South Center & & & & 7 & 7 & 5 & 61 & 67 & 63 & 32 & 27 & 31 \\
\hline North & & & & 4 & 4 & 4 & 31 & 35 & 38 & 65 & 61 & 58 \\
\hline East & & & & 15 & 11 & 9 & 65 & 61 & 58 & 20 & 28 & 32 \\
\hline All & & & & 6 & 5 & 6 & 41 & 44 & 46 & 54 & 51 & 48 \\
\hline
\end{tabular}

Source: Authors' calculations based on the mesolevel component of the Bangladesh fish value chain survey conducted by the International Food Policy Research Institute in 2014.

grew 63 percent, from 1.08 million in 2004 to 1.76 million in 2014, but the relative share of farm numbers across zones changed little over this period.

From the perspective of average household operated aquaculture land (pond surface), the average farm size changed little over the decade, even as the total population of them nearly doubled (Table 3.7). When the average area of aquaculture landholdings operated across zones between 2008 and 2013 is compared, the overall increase was moderate ( 7.2 percent). However, there was considerable variation between zones, with the North and the South Center registering the largest increases, up 19 percent from 0.3 hectares to 0.35 hectares, and 17 percent from 0.24 hectares to 0.28 hectares, respectively, with other zones registering little change.

Fish farming households sampled in the stacked survey operated 0.29 hectares of ponds in 2008 and 0.31 hectares of ponds in 2013. Fish farmers in Bangladesh hold on average 0.86 hectares of land (fish and nonfish land combined). Therefore they are located in the second upper land quintile of farmers in the country, and they have approximately double the 0.45 hectares average 
TABLE 3.6 Structural change in fish farmer clusters over 10 years

\begin{tabular}{|c|c|c|c|c|c|c|c|c|c|c|c|c|}
\hline \multirow[b]{4}{*}{ Zone } & \multicolumn{12}{|c|}{ Fish farmers } \\
\hline & & & & & & & are in $t$ & total nu & Imber $(\%$ & & & \\
\hline & \multicolumn{3}{|c|}{$\begin{array}{l}\text { Total number } \\
\text { ('000s) }\end{array}$} & \multicolumn{3}{|c|}{$\begin{array}{c}\text { of small } \\
(<0.2 \mathrm{ha})\end{array}$} & \multicolumn{3}{|c|}{$\begin{array}{l}\text { of medium } \\
(0.2-0.8 \mathrm{ha})\end{array}$} & \multicolumn{3}{|c|}{$\begin{array}{c}\text { of large } \\
(>0.8 \text { ha) }\end{array}$} \\
\hline & 2004 & 2009 & 2014 & 2004 & 2009 & 2014 & 2004 & 2009 & 2014 & 2004 & 2009 & 2014 \\
\hline Southwest & 335 & 417 & 494 & 15 & 17 & 17 & 41 & 41 & 46 & 44 & 42 & 37 \\
\hline South Center & 319 & 384 & 487 & 39 & 35 & 42 & 39 & 45 & 34 & 22 & 20 & 23 \\
\hline North & 343 & 474 & 634 & 43 & 46 & 45 & 34 & 33 & 32 & 23 & 21 & 23 \\
\hline East & 84 & 112 & 148 & 44 & 43 & 45 & 34 & 37 & 32 & 22 & 20 & 24 \\
\hline \multirow[t]{4}{*}{ All } & 1,081 & 1,388 & 1,763 & 33 & 34 & 36 & 37 & 39 & 37 & 29 & 27 & 27 \\
\hline & & & & \multicolumn{9}{|c|}{ Share in total pond area (\%) } \\
\hline & & & & \multicolumn{3}{|c|}{ of small } & \multicolumn{3}{|c|}{ of medium } & \multicolumn{3}{|c|}{ of large } \\
\hline & & & & 2004 & 2009 & 2014 & 2004 & 2009 & 2014 & 2004 & 2009 & 2014 \\
\hline Southwest & & & & 4 & 4 & 4 & 30 & 31 & 36 & 66 & 65 & 59 \\
\hline South Center & & & & 14 & 12 & 15 & 41 & 47 & 36 & 46 & 41 & 49 \\
\hline North & & & & 15 & 17 & 16 & 36 & 37 & 34 & 48 & 46 & 50 \\
\hline East & & & & 16 & 16 & 16 & 36 & 41 & 34 & 48 & 44 & 50 \\
\hline All & & & & 10 & 11 & 12 & 35 & 37 & 35 & 54 & 52 & 53 \\
\hline
\end{tabular}

Source: Authors' calculations based on the mesolevel component of the Bangladesh fish value chain survey conducted by the International Food Policy Research Institute in 2014.

landholding of rice farmers (Ahmed et al. 2013). However, they are smaller than a typical fish farmer in other countries in the region, such as Myanmar and Thailand. Furthermore, the average 0.31 hectares of pond area per fish farm in our sample is five times the average 0.06 hectares area of "homestead ponds" reported by Belton and Azad (2012) in Bangladesh. As previously mentioned, the survey sampling purposively selected districts with high concentrations of fish farming, which our household survey analysis shows tend to be correlated with higher shares of commercial farms and lower shares of (subsistence) homestead fish ponds.

Moreover, fish farming tends to be concentrated among the upper stratum of small farms. Figures extracted from Bangladesh Integrated Household Survey (BIHS) data show that 89 percent of the aquaculture households contributed just 25 percent of total production, while the top 2.4 percent of fish farming households accounted for 50 percent of total output. Our mesolevel survey data reflect this concentration. Larger farms constituted 27 percent of fish farms but had 53 percent of pond area in 2014, with little change in this 
TABLE 3.7 Landholdings and tenancy by year and zone

\begin{tabular}{|c|c|c|c|c|c|c|c|c|c|c|}
\hline \multirow[b]{2}{*}{ Zone } & \multicolumn{2}{|c|}{ Southwest } & \multicolumn{2}{|c|}{ South Center } & \multicolumn{2}{|c|}{ North } & \multicolumn{2}{|c|}{ East } & \multicolumn{2}{|c|}{ All } \\
\hline & 2008 & 2013 & 2008 & 2013 & 2008 & 2013 & 2008 & 2013 & 2008 & 2013 \\
\hline $\begin{array}{l}\text { Total nonfish land } \\
\text { overall (ha/HH) } \\
\text { (zeroes in average) }\end{array}$ & 0.26 & 0.31 & 0.45 & 0.54 & 0.38 & 0.42 & 0.33 & 0.39 & 0.34 & 0.40 \\
\hline $\begin{array}{l}\text { Total fish pond land (ha/ } \\
\text { HH) (zeroes in average) }\end{array}$ & 0.59 & 0.64 & 0.24 & 0.28 & 0.30 & 0.35 & 0.49 & 0.48 & 0.43 & 0.46 \\
\hline $\begin{array}{l}\text { Total operated land (used, } \\
\text { including owned and } \\
\text { rented-in lands) }\end{array}$ & 0.51 & 0.52 & 0.18 & 0.21 & 0.17 & 0.22 & 0.20 & 0.20 & 0.29 & 0.31 \\
\hline Self-owned & 0.36 & 0.33 & 0.12 & 0.12 & 0.10 & 0.11 & 0.05 & 0.05 & 0.18 & 0.17 \\
\hline $\begin{array}{l}\text { Joint-owned with } \\
\text { another } \mathrm{HH}\end{array}$ & 0.12 & 0.16 & 0.04 & 0.08 & 0.01 & 0.06 & 0.09 & 0.10 & 0.07 & 0.10 \\
\hline Rented in & 0.04 & 0.03 & 0.02 & 0.01 & 0.06 & 0.05 & 0.06 & 0.05 & 0.04 & 0.04 \\
\hline Rented out & 0.07 & 0.08 & 0.02 & 0.03 & 0.02 & 0.02 & 0.03 & 0.03 & 0.04 & 0.04 \\
\hline $\begin{array}{l}\text { Jointly owned, used by } \\
\text { other } \mathrm{HH}\end{array}$ & 0.01 & 0.03 & 0.04 & 0.04 & 0.10 & 0.11 & 0.25 & 0.24 & 0.10 & 0.10 \\
\hline Total land & 0.85 & 0.95 & 0.69 & 0.82 & 0.68 & 0.77 & 0.82 & 0.86 & 0.77 & 0.86 \\
\hline
\end{tabular}

Source: Authors' calculations based on the farm household component of the Bangladesh fish value chain survey conducted by the International Food Policy Research Institute in 2013.

Note: $\mathrm{HH}=$ household.

share since 2004. The share of area among farmers of other size categories also remained stable over this period, at around 35 percent for medium-size and 11 percent for small farms. This suggests that while many new producers have entered farming, there has been little if any consolidation into larger farm units.

Finally, Table 3.8 shows yields of 3.35 metric tons per hectare on average in the sample in 2013. The North has far higher land yields than the rest of the zones. This helps to explain why the concentration of farms in the North is low relative to the high concentration in the North of hatcheries, feed mills, and input dealers. The North simply has a much more intensive production technology, heavy in external inputs supplied by these off-farm enterprises, and that intensification is reflected in its extraordinary yields relative to the rest of the fish farming clusters. Absolute yield growth was greatest in the North, up from 5 metric tons per hectare to 10 metric tons per hectare, while in relative terms the East grew faster from a lower base of 1.3 metric tons per hectare to 2.9 metric tons per hectare. The South Center region grew from 
TABLE 3.8 Factor productivity in 2013

\begin{tabular}{lccccc}
\hline & Southwest & South Center & North & East & All \\
\cline { 2 - 6 } Observations in 2013 & 465 & 280 & 420 & 340 & 1,505 \\
\hline Total fish output (kg) per & & & & & \\
Labor day (own + hired) & 9.0 & 7.2 & 32.7 & 20.8 & 18.9 \\
Own labor day & 10.3 & 10.5 & 42.5 & 23.8 & 23.9 \\
Pond hectare (kg) & 801 & 2,565 & 10,017 & 2,916 & 3,352 \\
Capital (thousand BDT) & 5.3 & 9.8 & 25.2 & 10.2 & 13.0 \\
\hline
\end{tabular}

Source: Authors' calculations based on the farm household component of the Bangladesh fish value chain survey conducted by the International Food Policy Research Institute in 2013.

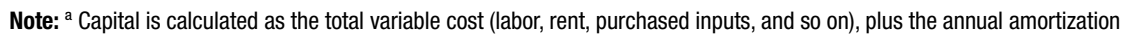
of quasi-fixed assets. BDT = Bangladeshi taka.

TABLE 3.9 Structural change in rural fish trader clusters over 10 years

\begin{tabular}{|c|c|c|c|c|c|c|c|c|c|c|c|c|}
\hline \multirow[b]{4}{*}{ Zone } & \multicolumn{12}{|c|}{ Rural fish traders } \\
\hline & & & & & & & $\operatorname{are~in~}$ & otal nu & Imber ( & & & \\
\hline & \multicolumn{3}{|c|}{$\begin{array}{l}\text { Total number } \\
\text { (hundreds) }\end{array}$} & \multicolumn{3}{|c|}{$\begin{array}{l}\text { of small } \\
(<1 \mathrm{MT})\end{array}$} & \multicolumn{3}{|c|}{$\begin{array}{l}\text { of medium } \\
(1-5 \mathrm{MT})\end{array}$} & \multicolumn{3}{|c|}{$\begin{array}{l}\text { of large } \\
\text { (> } 5 \mathrm{MT} \text { ) }\end{array}$} \\
\hline & 2004 & 2009 & 2014 & 2004 & 2009 & 2014 & 2004 & 2009 & 2014 & 2004 & 2009 & 2014 \\
\hline Southwest & 42 & 46 & 59 & 71 & 74 & 76 & 26 & 22 & 20 & 4 & 4 & 4 \\
\hline South Center & 24 & 33 & 38 & 61 & 59 & 45 & 28 & 26 & 35 & 11 & 15 & 20 \\
\hline North & 34 & 54 & 128 & 61 & 58 & 76 & 22 & 23 & 14 & 17 & 19 & 9 \\
\hline East & 48 & 74 & 88 & 68 & 74 & 71 & 24 & 21 & 23 & 8 & 6 & 6 \\
\hline \multirow[t]{4}{*}{ All } & 148 & 207 & 313 & 66 & 67 & 71 & 24 & 22 & 20 & 9 & 10 & 9 \\
\hline & & & & \multicolumn{9}{|c|}{ Share in total volume (\%) } \\
\hline & & & & \multicolumn{3}{|c|}{ of small } & \multicolumn{3}{|c|}{ of medium } & \multicolumn{3}{|c|}{ of large } \\
\hline & & & & 2004 & 2009 & 2014 & 2004 & 2009 & 2014 & 2004 & 2009 & 2014 \\
\hline Southwest & & & & 21 & 23 & 23 & 45 & 41 & 37 & 34 & 36 & 40 \\
\hline South Center & & & & 11 & 9 & 5 & 30 & 24 & 24 & 59 & 67 & 71 \\
\hline North & & & & 9 & 7 & 17 & 19 & 18 & 19 & 73 & 75 & 64 \\
\hline East & & & & 15 & 20 & 18 & 32 & 33 & 35 & 53 & 47 & 48 \\
\hline All & & & & 13 & 13 & 15 & 30 & 26 & 26 & 57 & 61 & 58 \\
\hline
\end{tabular}

Source: Authors' calculations based on the mesolevel component of the Bangladesh fish value chain survey conducted by the International Food Policy Research Institute in 2014. 
2 metric tons per hectare to 2.6 metric tons per hectare, while the Southwest remained stagnant at 0.8 metric tons per hectare.

\section{FISH WHOLESALE SEGMENT RESTRUCTURING}

The fish wholesale segment has expanded rapidly. This occurred with a proliferation, especially during the 2000s, of rural fish wholesale markets and an increase in fish wholesale markets in such cities as Dhaka. Fish trader numbers more than doubled across the four zones, from 14,800 in 2004 to 31,300 in 2014 (2.1 times versus 1.6 times for farmers) as shown in Table 3.9. The largest share of traders was in the North (41 percent) in 2014, which had only 23 percent of the traders in 2004. Trader startups followed the concentration of fish production; most village traders started about 10 to 15 years ago, over the same period as the beginning and development phase of the aquaculture boom.

\section{Commercialization and Spatial Elongation}

In Bangladesh, mainly since 2005, the value chain for farmed fish has commercialized and "lengthened" geographically. This is a typical trend in transformation and modernization of food supply chains, with concomitant interprovince market integration and reduction of transaction costs. This happened, for example, in rice and potatoes in Asia over the past decade (Reardon et al. 2012). The commercialization of fish farming is itself dependent on the proliferation of services discussed above: the development of off-farm components of the value chain permits a division of labor wherein small farmers can specialize in pond operations and enjoy cost savings via economies of scale, economies of scope, and economies of agglomeration by relying on the upstream feed and seed purveyers and downstream wholesale and logistic services that themselves are specialized enterprises. Belton, Ahmed, and Jahan (2014) contend that the availability of these services facilitates the entry of smaller producers into commercial fish farming; Reardon et al. (2012) contend similarly for rice and potato sectors. We discuss the trends of commercialization and chain lengthening below, from upstream to midstream.

\section{SEED COMMERCIALIZATION}

Farmers have shifted from trapping wild fish on their farms or buying locally available wild seed in the early 1990s (Ahmed, Rab, and Bimbao 1993) to stocking hatchery-produced seed in the 2000s. By 2011, 98 percent of fish seed was produced by private hatcheries (Belton et al. 2011). The shift to hatchery-produced seed resulted in a lengthening of the distances over which seed was traded, which evolved due to a mix of initial environmental and 
institutional conditions and the location of sources of demand. These trends have given rise to a situation in which there is a correlation of the level of activity of the broad cluster and the co-location of hatcheries. There is strong spatial concentration of hatcheries in the North, which has more than half of the hatcheries in the four zones. But our survey also found that on average half of what hatcheries produce is sold to buyers outside of their own district (not shown in the tables). Hatcheries thus tend to be "shared" across districts and even zones.

\section{FEED COMMERCIALIZATION}

The commercialization of aquaculture feeds and the geographical lengthening of that segment have occurred in lockstep. There has been a long-term shift from little use of feed of any type (Ahmed, Rab, and Bimbao 1993) to use of feed available on-farm (for example, cow manure, rice bran), to purchase of the latter, and increasingly to purchase of formulated pelleted feeds; 90 percent of the latter are made by medium- and large-scale commercial mills in 2015 (Mamun-Ur-Rashid et al. 2013).

Large feed mills in the peri-urban industrial zone north of Dhaka, where most feedlot poultry farming occurs, distribute feed throughout the country. Mills are concentrated there for centralized acquisition of inputs and because (similar to other countries) many fish feed manufacturers originally produced poultry feeds before diversifying into fish feed by adding additional lines. Of the 25 largest poultry feed mills in Bangladesh, 18 also produce fish feeds (Khaleduzzaman and Khandaker 2009).

The input acquisition supply chain for feed manufacture stretches over long distances. Most dried fish, one of the main ingredients in fish feed, is sourced from marine fisheries in coastal districts of Bangladesh but is increasingly also imported, as is soy (another key ingredient). Meat and bone meals, important protein sources for feed, are sourced from the European Union (Mamun-Ur-Rashid et al. 2013). Much of the equipment used in the value chain (for example, feed milling machines, vehicles, pumps, cold chain equipment) is imported, mainly from East and Southeast Asia, as are chemicals (Mamun-Ur-Rashid et al. 2013). As elsewhere in Asia, foreign expertise has played an important role in the development of hatchery and feed operations (Belton 2012). For instance, internationally led training received by Bangladeshi entrepreneurs has been important in the establishment of monosex tilapia hatcheries. Over time, dependence on these sources of information has lessened as technical knowledge has become more widely available within Bangladesh. 


\section{FISH FARM COMMERCIALIZATION}

The shift from subsistence to commercial production in the fish sector occurred as initially fish were only home-consumed from the household pond, then increasingly sold into nearby markets, and then also marketed to more distant urban markets. These sequential changes have occurred rapidly. As recently as the early 1990s, Ahmed, Rab, and Bimbao (1993) observed that only a small fraction of total harvested farmed fish entered the market outside the local village.

In contradiction to the traditional view of fish farming in Bangladesh as mainly subsistence oriented, the value chain survey of the farm segment shows that 75 percent of households who engage in fish farming sell fish. Strikingly, the share of farms with a marketed surplus even in these dense aquaculture clusters was only 57 percent just five years prior to this, indicating that extremely rapid commercialization occurred. The Southwest has the highest share of fish farming households marketing fish (88 percent), in line with shrimp and prawn production in that zone. Figures are around 70 to 75 percent for the South Center and the North, and 60 percent for the less advanced (in terms of fish farming) East.

Table 3.10 shows the disposal of fish output by aquaculture households in 2013 by final user type (note that only 8 percent of the fish was home consumed). Interestingly, although yields differ significantly across zones, the marketed surplus rate does not-the home consumption share is 4 percent in the North zone and about 15 percent in the other zones. Moreover, in contrast to the common image of the rural fish market being dominated by small rural brokers, the market has shifted to rural sourcing by large wholesalers based in towns and secondary cities. Tables 3.10 and 3.11 show that about two-thirds of the marketed volume goes to large wholesalers; again, that differs between the North with 68 percent and the average of the other zones at about 54 percent. By contrast, local rural brokers have a mere 5 percent share of the market as shown in Table 3.11. Just over a decade earlier, fish farmers usually sold their fish to local traders or fish collectors (ADB 2005). Interestingly, this is the same market structure development that has occurred in rice and potatoes in Asia (Reardon et al. 2012).

\section{RISE OF THE FISH TRADER SEGMENT TO URBAN AREAS}

Growth in sales of farm output has been accompanied by a proliferation of traders in the midstream segment of the chain. As urban demand has grown and the road network has developed (see Table 3.2), fish is increasingly sold by traders in the zones of production to Dhaka and from one division to another. The national Household Income and Expenditure Survey (HIES) (BBS 2012) 
TABLE 3.10 Disposal of fish farm harvest by final user type, 2013

\begin{tabular}{lccccc}
\hline & Southwest & South Center & North & East & All \\
\cline { 2 - 6 } Observations in 2013 & \multicolumn{1}{c}{465} & $\mathbf{2 8 0}$ & 420 & 340 & 1,505 \\
\hline Share of farmers who grow & 87.5 & 70.7 & 74.5 & 59.7 & 74.5 \\
fish selling fish & & & & & \\
Farmer's own consumption & 15.4 & 18.5 & 4.2 & 12.2 & 8.4 \\
Sales through different & & & & & \\
value chains & & & & & \\
Consumed by another farm & 0.3 & 0.0 & 0.0 & 0.0 & 0.0 \\
household & & & & & \\
Direct consumer & 0.0 & 0.7 & 0.9 & 0.0 & 0.7 \\
Retailer at traditional market & 11.4 & 7.7 & 2.7 & 15.6 & 6.0 \\
Assembler (collector) & 5.6 & 2.8 & 8.1 & 14.7 & 8.4 \\
Large wholesaler & 49.2 & 54.5 & 68.1 & 56.4 & 62.8 \\
Supplier (broker) & 1.5 & 8.6 & 8.7 & 0.6 & 6.6 \\
Supermarket & 0.0 & 0.0 & 0.0 & 0.0 & 0.0 \\
Auctioned & 16.6 & 7.1 & 7.3 & 0.5 & 7.1 \\
Others & 0.1 & 0.0 & 0.0 & 0.0 & 0.0 \\
Total & 100.0 & 100.0 & 100.0 & 100.0 & 100.0 \\
\hline
\end{tabular}

Source: Authors' calculations based on the farm household component of the Bangladesh fish value chain survey conducted by the International Food Policy Research Institute in 2013.

Note: "Large wholesaler" refers to the top wholesalers in the market.

shows that from 2000 to 2005 the share of fish consumed in urban areas rose from 29 percent to 42 percent.

The conduct of the segment has also changed from the traditional image common in Asia that traders are advancing funds to farmers to lock in farmers in transactions. Our survey showed that none of the farmers received any cash advance from fish traders. That was confirmed by our trader survey. But the trader survey showed that around 40 percent of traders, both rural (operating from villages) and rural-urban (operating from secondary cities or towns), provide advances of working capital to other traders to secure supplies of fish, with an average loan duration of just under one month.

Among rural and rural-urban traders, our survey shows that the great majority have stalls in rural and rural-urban wholesale markets. Most rural fish traders ( 63 percent) and rural-urban traders ( 79 percent) take a commission on the transaction of fish (rather than through arbitrage where they buy and then sell). None of the rural traders and few of the rural-urban traders surveyed owned trucks, and only 6 percent rented them, indicating their role as intermediaries who operate from a base and just link buyers and sellers, 
TABLE 3.11 Disposal of fish farm harvest by final user location, 2013

\begin{tabular}{|c|c|c|c|c|c|}
\hline \multirow[b]{2}{*}{ Observations in 2013} & \multicolumn{2}{|c|}{ Southwest South Center } & \multirow{2}{*}{$\begin{array}{c}\text { North } \\
420\end{array}$} & \multirow{2}{*}{$\begin{array}{c}\text { East } \\
340\end{array}$} & \multirow{2}{*}{$\begin{array}{c}\text { All } \\
1,505\end{array}$} \\
\hline & 465 & 280 & & & \\
\hline Farmer's own consumption & 15.4 & 18.5 & 4.2 & 12.2 & 8.4 \\
\hline \multicolumn{6}{|l|}{ Sales through different value chains } \\
\hline Consumed by another farm household & 0.3 & 0.0 & 0.0 & 0.0 & 0.0 \\
\hline Direct consumer & 0.0 & 0.7 & 0.9 & 0.0 & 0.7 \\
\hline $\begin{array}{l}\text { Retailer at local (village, union, upazila) } \\
\text { traditional market }\end{array}$ & 11.4 & 7.7 & 2.7 & 15.6 & 6.0 \\
\hline Assembler locally & 5.6 & 2.6 & 5.5 & 14.7 & 6.7 \\
\hline Assembler in same district & 0.0 & 0.2 & 2.5 & 0.0 & 1.7 \\
\hline Large wholesaler locally & 46.3 & 46.7 & 64.4 & 31.8 & 55.5 \\
\hline Large wholesaler in same district & 2.7 & 4.3 & 2.9 & 14.8 & 4.9 \\
\hline Large wholesaler in different district & 0.1 & 3.5 & 0.8 & 9.7 & 2.3 \\
\hline Supplier (broker) locally & 1.2 & 8.6 & 6.9 & 0.6 & 5.4 \\
\hline Supplier (broker) in same district & 0.3 & 0.0 & 0.0 & 0.0 & 0.0 \\
\hline Supplier (broker) in different district & 0.0 & 0.0 & 1.8 & 0.0 & 1.2 \\
\hline Supermarket & 0.0 & 0.0 & 0.0 & 0.0 & 0.0 \\
\hline Auctioned locally & 16.3 & 5.4 & 1.9 & 0.0 & 3.4 \\
\hline Auctioned in same district & 0.1 & 1.1 & 5.3 & 0.0 & 3.6 \\
\hline Auctioned in different district & 0.2 & 0.6 & 0.1 & 0.5 & 0.2 \\
\hline Others & 0.1 & 0.0 & 0.0 & 0.0 & 0.0 \\
\hline Total & 100.0 & 100.0 & 100.0 & 100.0 & 100.0 \\
\hline
\end{tabular}

Source: Authors' calculations based on the farm household component of the Bangladesh fish value chain survey conducted by the International Food Policy Research Institute in 2013.

relying on hiring transporters (or having the farmer hire transporters) to deliver. The average monthly working capital of rural traders was a little under half that of rural-urban traders, as expected.

Few traders (less than 2 percent) owned ice-making plants, and almost none owned cold storage. Only 31 percent of rural traders and 20 percent of rural-urban traders reported icing the fish. This likely reflects their role as commission agents, who rapidly broker sales between buyers and sellers, without taking possession of the fish themselves, with buyers usually assuming responsibility for procuring ice from ice suppliers or manufacturers. The low ice use rate is not for lack of access to ice firms: $80-90$ percent of traders felt they had good access to ice firms. The domestic market demands whole fresh fish, with little if any value addition occurring. It is thus not observed that wholesalers, feed companies, or hatcheries process their own fish. 


\section{Technological cum Product Composition/Product Cycle Change and Patterns}

Important interlinked changes have occurred in the technologies and the product composition of farm production concurrent with the above structural changes in the value chain.

\section{THE PRODUCT CYCLE}

The product cycle is a widely observed feature of product development in many sectors of the economy, which can be observed for a range of agricultural sectors, including fish and fruit, in a number of other countries. Sequentially, the five stages of the product cycle are (1) the local niche product stage; (2) the commodity stage, during which a local (or exotic) niche product is "commoditized" by production in large quantities, driving down costs, but with little product variety or quality differentiation; (3) the product differentiation stage, when the commodity becomes differentiated along the lines of several possible tangible and intangible attributes (for example, variety, quality, organic versus conventional, confined versus free range); (4) the commoditization stage, where the differentiated products are themselves produced on larger scale and commoditized; and (5) the introduction of new niche or differentiated products. The cycle can continue indefinitely depending on the capacity of innovation in the sector and the market.

We posit that the Bangladesh fish sector has followed a typical product cycle development path, facilitated by the linked technology changes along the value chain described above, although to date only the three stages can be discerned. The first (and ongoing) technology change linked to the first product cycle step (moving from niche to commodity) is the shift from capture of wild fish stocks from open waters to their production in ponds under controlled conditions. This shift began in earnest during the 1980s, as ponds were increasingly used for aquaculture, primarily by stocking native carp species, an important component of inland capture fisheries at that time (Ali 1997). As the decades progressed, additional species were introduced and commoditized, such as exotic carps in the 1980s, pangas in the mid-1990s, and monosex Nile tilapia in the early 2000s (Ali, Haque, and Belton 2013; Belton and Little 2011). Later, in the late 2000s, many additional native fish that were formerly available only from domestic capture fisheries were incorporated into farm production.

Data from BIHS depict the consumption side of the product cycle (Figure 3.1). After becoming commoditized during the 2000s, pangas and 
FIGURE 3.1 Average weekly consumption per capita of the 10 most consumed fish species in rural Bangladesh

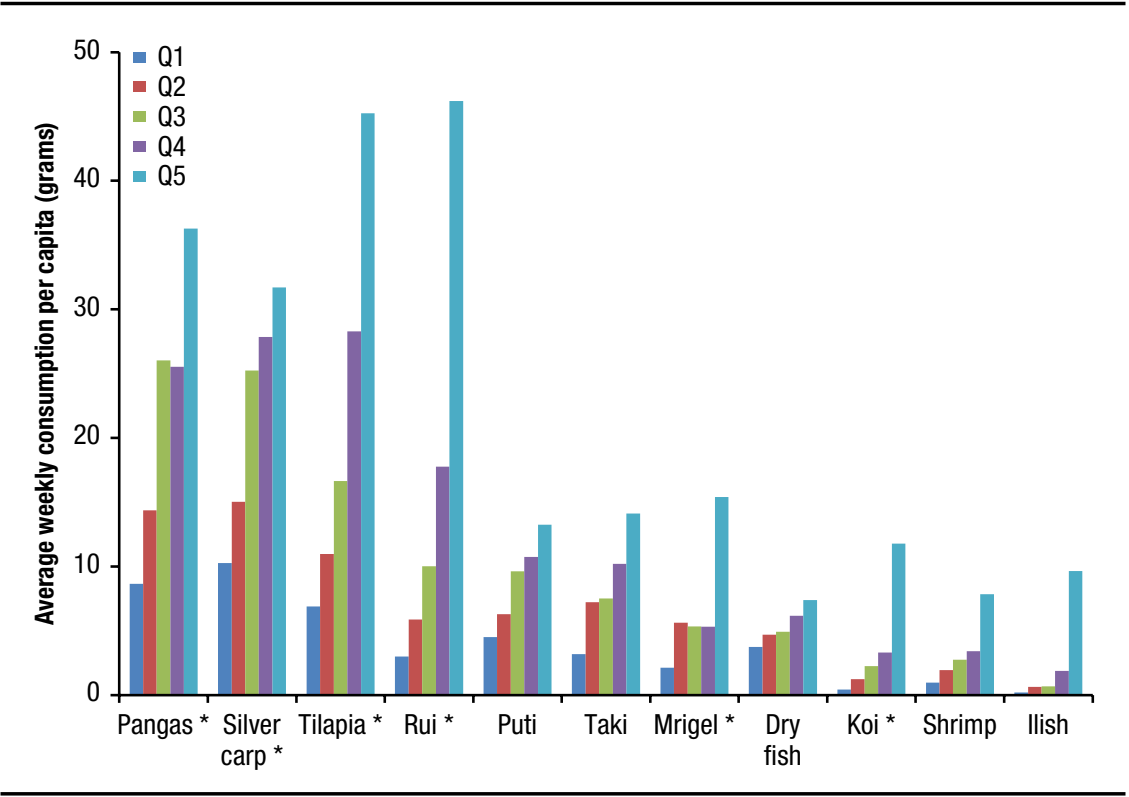

Source: Derived by authors from the BIHS 2011-2012 dataset (Ahmed 2013).

Note: $Q 1$ = expenditure quintile 1, and so on; fish marked with an asterisk are produced predominantly from aquaculture.

tilapia are now, respectively, the first and third most consumed fish in rural areas of Bangladesh. Rui, an indigenous carp species that was among the first fish to be commoditized and traditionally the most important farmed fish, is now ranked fourth in terms of consumption. The recently commoditized koi now ranks eighth. This change has occurred quickly. Comparison with similar household survey data collected in 2006-2007 shows rui still as the most consumed fish at that time, with pangas third, tilapia ninth, and koi not yet produced in sufficient quantities to feature (Belton, van Asseldonk, and Thilsted 2014).

Our farm survey also shows evidence of product cycle changes from the production side in each zone in 2008 compared with 2013 (Table 3.12). There is a significant increase in production of pangas, tilapia, and niche species in the North as well as niche species in the East. It is interesting that production of niche species has increased slightly in the study zones, but in the North increased 72 percent, and in the East increased 16 times, though from a low base. 
TABLE 3.12 Aquaculture production by fish category, 2008 and 2013

\begin{tabular}{|c|c|c|c|c|c|c|c|c|c|c|}
\hline \multirow[b]{2}{*}{ Zone } & \multicolumn{2}{|c|}{ Southwest } & \multicolumn{2}{|c|}{ South Center } & \multicolumn{2}{|c|}{ North } & \multicolumn{2}{|c|}{ East } & \multicolumn{2}{|c|}{ Total } \\
\hline & 2008 & 2013 & 2008 & 2013 & 2008 & 2013 & 2008 & 2013 & 2008 & 2013 \\
\hline \multicolumn{11}{|l|}{ Production (kg/year) } \\
\hline Carps & 173 & 175 & 235 & 325 & 521 & 928 & 233 & 369 & 291 & 445 \\
\hline Tilapia & 58 & 71 & 60 & 99 & 182 & 503 & 169 & 309 & 116 & 244 \\
\hline Pangas (yellowtail catfish) & 0 & 0 & 66 & 105 & 544 & 1,358 & 103 & 207 & 180 & 401 \\
\hline Shrimp & 129 & 134 & 7 & 8 & 0 & 0 & 12 & 7 & 48 & 51 \\
\hline Niche & 46 & 45 & 58 & 69 & 186 & 408 & 18 & 285 & 172 & 200 \\
\hline Others & 42 & 46 & 60 & 70 & 92 & 216 & 94 & 137 & 70 & 117 \\
\hline Total & 448 & 470 & 485 & 675 & 1,525 & 3,414 & 630 & 1,314 & 876 & 1,458 \\
\hline \multicolumn{11}{|l|}{ Share of production (\%) } \\
\hline Carps & 39 & 37 & 49 & 48 & 34 & 27 & 37 & 28 & 33 & 31 \\
\hline Tilapia & 13 & 15 & 12 & 15 & 12 & 15 & 27 & 24 & 13 & 17 \\
\hline Pangas (yellowtail catfish) & 0 & 0 & 14 & 16 & 36 & 40 & 16 & 16 & 21 & 28 \\
\hline Shrimp & 29 & 28 & 1 & 1 & 0 & 0 & 2 & 1 & 5 & 3 \\
\hline Niche & 10 & 9 & 12 & 10 & 12 & 12 & 3 & 22 & 20 & 14 \\
\hline Others & 9 & 10 & 12 & 10 & 6 & 6 & 15 & 10 & 8 & 8 \\
\hline
\end{tabular}

Source: Authors' calculations based on the farm household component of the Bangladesh fish value chain survey conducted by the International Food Policy Research Institute in 2013.

\section{CAPITAL-LED INTENSIFICATION}

The conventional image of the pond-fish sector was once millions of backyard "homestead ponds," used primarily for subsistence (home consumption). Dey, Bose, and Alam (2008) refer to aquaculture in Bangladesh as a "lowinput activity for household consumption." However, the small and mediumsize commercial farms that now dominate aquaculture output are making a transition from the traditional production technologies toward intensification-first by labor and then by productive capital (such as formulated feed and medicines and some equipment such as aeration). The main technology changes observed in the survey are as follows.

\section{Rapid increase of purchased seed and feed}

Use of wild fish seed has been replaced by use of hatchery produced fish seed. Jahan et al. (2015) report that fewer than 4 percent of farmers use fish seed from open-water sources. Seed stocking density has also increased. Our farm survey shows that nominal expenditure on fingerlings per hectare more than doubled between 2008 and 2013. Moreover, there has been a transition in zones surveyed from no use of feed, to use of feed inputs available on-farm, 
to use of handmade feeds made with ingredients purchased off-farm, to the use of purchased manufactured feeds, formulated to meet the complete nutritional requirements of the fish produced and, increasingly, from formulated sinking feed to floating formulated feed. The latter allows for greater production efficiencies via reduction of waste and higher digestibility if the pond is stocked with medium- and top-dwelling fish (Mamun-Ur-Rashid et al. 2013).

Strikingly, our farm survey showed that 38 percent of farmers in 2013 used commercial pelleted feeds, up from 30 percent in 2008; both figures are surprisingly high and run counter to the common image of fish farming in Bangladesh as mostly extensive or semi-intensive (ADB 2005). Use of commercially manufactured pelleted feeds is significant because their use can increase fish growth rates, facilitating higher yields, and is consistent with product cycle-driven diversification into species of fish (for example, pangas, tilapia, koi) that require formulated diets to attain optimal growth (MamunUr-Rashid et al. 2013).

Our survey results show that use of other supplementary feeds usually associated with semi-intensive farming (for example, rice bran, mustard oilcake) was already widespread in 2008 (60 percent of farmers) but grew to 69 percent of farmers by 2013. This indicates a range of stages of intensification, with some farmers shifting from extensive to semi-intensive production and others "upgrading" to more intensive production with pelleted feeds.

\section{Rapid increase in the use of chemicals}

Use of medicines and other chemicals_-including lime, antibiotics, salt, fungicides, insecticides, and feed additives such as vitamins-have increased in line with higher stocking densities and feed use. This has occurred as the incidence of disease has increased and better management has been necessary to maintain water quality within the parameters required for fish survival and growth (Ali et al. 2016).

Our farm survey shows that use of lime for pond preparation was already a widespread practice in 2008 (63 percent of farmers) and was adopted by 73 percent of farmers by 2013 . Use of medicines and vitamins was less common (6 percent of farms in 2013), increasing slightly from 4 percent in 2008. Use of both these inputs was greatest in the North, reflecting its intensified technology, and lowest in the least commercial zone, the East.

\section{Increase of use of hired labor}

Hired labor use has increased along with the overall need for labor. Whereas in the early 1990s, aquaculture used little household labor as compared to crop or livestock cultivation (Ahmed, Rab, and Bimbao 1993), commercial forms 
of aquaculture in Bangladesh now generate higher average demand for hired labor per unit area of land than paddy cultivation, due in part to the long fish cropping cycles (Belton, Ahmed, and Jahan 2014) and more yield and input use to manage. Our farm survey data show that both total labor inputs and inputs of hired labor have intensified per unit of (pond) land. The total outlay per hectare for labor (family plus hired) in 2013 was 1.6 times what it was in 2008. The share of hired (nonfamily) labor in total labor (hired plus own labor) increased from 11 percent to 21 percent over the same period.

Hiring labor was concentrated among a small subset of commercial farms. The share of farms hiring casual workers was 16 percent for pond preparation, 5 percent for stocking, 5 percent for the post-stocking/growing-out stage, and 6 percent for harvesting. The share of farms hiring salaried or permanent laborers was much lower still. Moreover, differences in total labor inputs and in hired labor varied markedly across zones, in line with patterns of intensification. The capital to labor ratio in 2008 was more than 50 percent higher in the Southwest and North than in the South Center and East (Table 3.13). By 2013 these differences are even more extreme, with capital-to-labor ratio in the Southwest and North more than 100 percent higher than in the South Center and East.

\section{Rapid increase/investment in quasi-fixed capital (equipment)}

There was substantial investment by fish farmers in productive capital. Investments (at nominal dollar rates) in assets used for fish farming jumped by 235 percent over 2008-2013. ${ }^{1}$ The rate of investment was similar over all zones, with the exception of the South Center, which was somewhat slower. However, the rapid jump in productive fish-related capital holdings masks the fact that few fish farms had these. Pumps, owned by 14 percent of households, were by far the most frequently owned item. Investment growth was thus from a relatively concentrated base among the small and medium-size commercial farms. The dollar value of the stock of quasi-fixed capital inputs (the rate of investment in capital) on fish farms rose faster than labor flow (total use of labor, measured in value terms) from 2008 to 2013.

Investment in agricultural equipment by fish farmers was reflected in productive capital stocks used for crop farming increasing by 185 percent. This too was similar across zones. Fish farmers also invested in livestock (increasing by 533 percent), while nonfarm productive assets climbed 730 percent and consumer durables by 240 percent. Even discounting these rates for inflation,

1 Assets used in fish farming were calculated by the summation of the value of the following common assets: pumps, generators, aerators, nets, weighing scales, boats, bicycles, motorcycles, pickup trucks, and trucks. 
TABLE 3.13 Fish farm capital-to-labor ratio by year and zone

\begin{tabular}{lccccc}
\hline Item & Southwest & South Center & North & East & All \\
\hline Capital-to-labor ratio (2013) & 1.52 & 0.39 & 0.63 & 0.48 & 0.75 \\
Capital-to-labor ratio (2008) & 0.96 & 0.33 & 0.47 & 0.32 & 0.51 \\
Change, 2008 to 2013 (\%) & 58 & 18 & 34 & 50 & 47 \\
\hline
\end{tabular}

Source: Authors' calculations based on the farm household component of the Bangladesh fish value chain survey conducted by the International Food Policy Research Institute in 2013.

these findings show that fish farmers were a vibrant capital-accumulating segment.

In conclusion, from 2008 to 2013 there was a remarkable increase in use of external inputs by farms. Total outlay on external inputs (feed, fertilizer, chemicals, and so on) tripled per hectare. The rate of external input use did not differ a great deal across three of the four zones. Average expenditure on inputs was much greater in the North however, reflecting the intensive technologies used there. Despite the rapid increase in total outlay on external inputs, the composition of that outlay was stable. Feed remained central, accounting for 78-79 percent of external input costs in both 2008 and 2013. Chemical fertilizer stayed at 5 percent; fuel $7-8$ percent; and pesticide and lime 5-6 percent. $^{2}$ Fifty percent of farmers (with a lower share in the East) used chemical fertilizer in the prestocking phase, up sharply from 39 percent. Use of other inputs also increased: 75 percent of farms used lime for pond preparation in 2013, up from 63 percent, and a third used water pumps for filling the pond in 2013, up from one-fifth, both indicating greater attention to maintenance of good water quality. In combination, these trends all point to a broad shift away from "traditional" low input forms of production, with capital intensification in the farm sector occurring in step with rapid growth, diversification, and technological change in the feed and seed value chain segments.

\section{Mirroring of Farm Capital-Led Intensification: Growth and Technological Change in the Input Supply Segments}

Capital intensification in the farm sector has occurred in step with rapid growth and diversification in upstream value chain segments, most importantly feed and seed. As noted previously, there has been a proliferation of feed mills but overall a concentration of production in larger mills. Larger feed mills

2 Fertilizer is used to induce growth of phytoplankton in the pond, which provides a natural feed for fish. 
have multiple lines and differentiate feed types for different fish species and age groups by protein content, complementing the species differentiation taking place on farms and in hatcheries in line with the product cycle. The most recent shift in feed mill technology has come about through the use of extrusion machinery to produce feeds that float instead of sink, providing further product differentiation and offering efficiency gains to producers. Mamun-UrRashid et al. (2013) found that from 2008 to 2012 production of formulated fish feeds almost tripled from 360,000 metric tons to an estimated 1 million metric tons. The share of floating feeds in total formulated feed production grew from less than 5 percent to close to 20 percent. The extrusion equipment used to manufacture floating feed represents a major investment. The size of mill and adoption of extrusion are closely correlated, and big mills dominate the floating feed supply. This factor may result in further concentration in the industry over time. The growing use of formulated feed has also seen rapid expansion in the number of fish feed dealers (both wholesalers and retailers), as noted previously, and veterinary chemical/medicine input retailers.

Technological shifts have also occurred within the seed supply segment of the value chain. The product cycle is observed in hatcheries, mirroring farm production-the share of hatcheries reporting carps to be the most important species sold fell from 59 percent to 45 percent over 2008 to 2013, while the share of hatcheries reporting pangas and tilapia (combined) as their most important species rose from 15 percent to 20 percent and the share of "niche" species jumped from 11 percent to 26 percent.

\section{Conclusion}

The chapter has produced a single, powerful finding: the fish value chain in Bangladesh is growing and transforming rapidly, in all segments. The quiet revolution in the fish value chain is a domestic market revolution. Dynamism of the aquaculture value chain in Bangladesh was shown in two interlinked ways.

First, there has been a tripling of volumes and actors in all the segments of the value chain since 2008. Also, there has been rapid capital deepening in the form of investments by hundreds of thousands of actors in the fish value chain. This is apparent in a great jump in feed use, investment in equipment and pond construction, and investments in mills, hatcheries, and vehicles. These investments have been made by, and provided opportunities for, a multitude of smallholder farmers as well as small and medium-size enterprises throughout the chain. Second, there has been diversification and 
specialization beyond carps into production of commercial species such as tilapia and pangas, which have raised yields and helped to move the fisheries sector along the product cycle. One important positive externality of this process has been a reduction in the price of farmed fish over time, making an important contribution to food security.

\section{References}

ADB (Asian Development Bank). 2005. An Evaluation of Small-Scale Freshwater Rural Aquaculture Development for Poverty Reduction. Operations Evaluation Department. Manila.

Ahmed, A. 2013. Bangladesh Integrated Household Survey (BIHS) 2011-2012. Washington, DC: International Food Policy Research Institute (IFPRI).

Ahmed, A. U., K. Ahmad, V. Chou, R. Hernandez, P. Menon, F. Naeem, F. Naher, W. Quabili, E. Sraboni, B. Yu, and Z. Hassan. 2013. The Status of Food Security in the Feed the Future Zone, and Other Regions of Bangladesh: Results from the 2011-2012 Bangladesh Integrated Household Survey. Washington, DC: IFPRI.

Ahmed, M., M. Abdur Rab, and M. P. Bimbao. 1993. Household Socioeconomics, Resource Use and Fish Marketing in Two Thanas of Bangladesh. Manila: International Center for Living Aquatic Resources Management (ICLARM).

Ali, H., M. M. Haque, and B. Belton. 2013. "Striped Catfish (Pangasianodon hypophthalmus, sauvage, 1878) Aquaculture in Bangladesh: An Overview." Aquaculture Research 44 (6): $950-965$.

Ali, H., A. Rico, K. Murshed-E-Jahan, and B. Belton. 2016. "An Assessment of Chemical and Biological Product Use in Aquaculture in Bangladesh." Aquaculture 454: 199-209.

Ali, M. Y. 1997. Fish, Water and People: Reflections on Inland Openwater Fisheries Resources of Bangladesh. Dhaka: University Press Ltd.

Bangladesh, DoF (Department of Fisheries). 1994. Fisheries Statistical Year Book of Bangladesh 19921993. Dhaka: Fisheries Resource Survey System, DoF, Ministry of Fisheries and Livestock.

1997. Fisheries Statistical Year Book of Bangladesh 1995-1996. Dhaka: Fisheries Resource

Survey System, DoF, Ministry of Fisheries and Livestock.

- 2006. Fisheries Statistical Year Book of Bangladesh 2004-2005. Dhaka: Fisheries Resource Survey System, DoF, Ministry of Fisheries and Livestock.

- 2015. Fisheries Statistical Year Book of Bangladesh 2013-2014. Dhaka: Fisheries Resource Survey System, DoF, Ministry of Fisheries and Livestock.

BBS (Bangladesh Bureau of Statistics). 2007. Statistical Yearbook of Bangladesh 2005. Dhaka. 
-2016. Statistical Yearbook of Bangladesh 2015. Dhaka: Ministry of Planning, People's Republic of Bangladesh.

Belton, B. 2012. "Culture, Social Relations and Private Sector Development in the Thai and Vietnamese Fish Hatchery Sectors." Asia Pacific Viewpoint 53 (2): 133-146.

Belton, B., N. Ahmed, and K. M. Jahan. 2014. Aquaculture, Employment, Poverty, Food Security and Well-Being in Bangladesh: A Comparative Study. Penang, Malaysia: CGIAR Research Program on Aquatic Agricultural Systems.

Belton, B., and A. Azad. 2012. "The Characteristics and Status of Pond Aquaculture in Bangladesh.” Aquaculture 358: 196-204.

Belton, B., M. Karim, S. Thilsted, K. Murshed-E-Jahan, W. Collis, and M. Phillips. 2011. "Review of Aquaculture and Fish Consumption in Bangladesh." Studies and Reviews 2011-53. Penang, Malaysia: The WorldFish Center.

Belton, B., and D. C. Little. 2011. "Immanent and Interventionist Inland Asian Aquaculture Development and Its Outcomes." Development Policy Review 29 (4): 459-484.

Belton, B., I. J. M. van Asseldonk, and S. H. Thilsted. 2014. "Faltering Fisheries and Ascendant Aquaculture: Implications for Food and Nutrition Security in Bangladesh.” Food Policy 44: $77-87$.

Crow, B. 2001. Markets, Class and Social Change: Trading Networks and Poverty in Rural South Asia. New York: Palgrave.

Dey, M. M., M. L. Bose, and M. F. Alam. 2008. Recommendation Domains for Pond Aquaculture. Country Case Study: Development and Status of Freshwater Aquaculture in Bangladesh. Penang, Malaysia: WorldFish.

Jahan, K. M., B. Belton, H. Ali, G. C. Dhar, and I. Ara. 2015. Aquaculture Technologies in Bangladesh: An Assessment of Technical and Economic Performance and Producer Behavior. Penang, Malaysia: WorldFish.

Khaleduzzaman, A. B. M., and Z. H. Khandaker. 2009. "Commercial Feed Production and Quality Control: Present Status and Future Prospects in Bangladesh.” In Proceedings of the Sixth International Poultry Show and Seminar. Dhaka: World Poultry Science Association, Bangladesh Branch.

Mamun-Ur-Rashid, M., B. Belton, M. Phillips, and K. A. Rosentrater. 2013. Improving Aquaculture Feed in Bangladesh: From Feed Ingredients to Farmer Profit to Safe Consumption. Penang, Malaysia: WorldFish.

Reardon, T., K. Chen, B. Minten, and L. Adriano. 2012. The Quiet Revolution in Staple Food Value Chains: Enter the Dragon, the Elephant, and the Tiger. Manila: Asian Development Bank; Washington, DC: International Food Policy Research Institute. 